\title{
48 Integrated management of Meloidogyne chitwoodi and M. fallax in potato: A complicated agronomical puzzle in the Netherlands and Belgium
}

\author{
Johnny Visser ${ }^{1, \star}$ and Wim M.L. Wesemael ${ }^{2}$ \\ ${ }^{1}$ Wageningen University \& Research Field Crops, Lelystad, The Netherlands; \\ ${ }^{2}$ Flanders Research Institute for Agriculture, Fisheries and Food (ILVO), \\ Merelbeke, Belgium
}

\begin{abstract}
Introduction
Meloidogyne chitwoodi and M. fallax have been important nematode problems in arable farming in the Netherlands and Belgium ever since their detection in the 1980s. Their quarantine status and the damage inflicted on product quality in important cash crops such as potato, carrots, black salsify and gladiolus has increased drastically the need for integrated nematode management strategies that prevent yield losses and further spreading.
\end{abstract}

\section{Economic importance}

The Netherlands is a major producer of ware, starch and especially seed potatoes. Belgium is the largest exporter of frozen potatoes in the world (www.fao.org/faostat, accessed 10 November 2020). Meloidogyne chitwoodi and M. fallax occur in several potato growing areas in the Netherlands and Belgium and can cause severe quality damage rendering them unsuitable for the market. Due to the EU quarantine status of these root-knot nematodes, potato seed tubers have to be free from infection by these two species before being allowed to enter EU traffic. They are a major threat to seed potato production in the Netherlands.

External galling of potato tubers caused by infection of $M$. chitwoodi or $M$. fallax reduces the commercial value of ware potatoes. The extent of this varies depending on the degree of deterioration and what the potato market will accept. Seed potatoes must be free of M. chitwoodi and M. fallax. In the event of an infection, the phytosanitary certificate is refused and the potato lot can only be sold as ware potatoes when not highly deteriorated or for cattle feed. As such, more than $50 \%$ of its economic value is lost. Estimates on economic losses due to root-knot nematodes in ware and seed potatoes are complex and accurate data on the actual financial damage caused by M. chitwoodi and M. fallax are difficult to obtain. However, economic losses most probably exceed $€ 1$ million per year. Meloidogyne chitwoodi and M. fallax do not cause any economic loss in the production of starch potato because these nematodes only inhibit growth at very high densities and seldom reduce overall yield (galling of tubers is not a quality issue in

* Corresponding author: johnny.visser@wur.nl 
starch potato). However, in Belgium, the phytosanitary measures implied make it impossible to grow potatoes when $M$. chitwoodi or M. fallax are detected in a field regardless of the ultimate market targeted.

Economic losses due to the two species is not limited to quality reduction of potato tubers but also to infections on other rotation crops. Other crops in rotations can be seriously infected (carrot, black salsify) and leads to the need for nematode management and intensive soil sampling for detection that generates extra production costs for growers (Wesemael et al., 2011).

\section{Host range}

Meloidogyne chitwoodi and M. fallax are closely related species and have a broad host range of monocot as well as dicotyl crops, including several major cash crops, cover crops and weeds (Den Nijs et al., 2004; Rich et al. 2009). When planning a crop rotation it is also important to be aware of the difference between the host range of M. chitwoodi and M. fallax. Sugar beet, for example, is a very good host for M. fallax but a rather poor host for $M$. chitwoodi. Detailed information can be found in the databases of the EU project Best4Soil (www.best4soil.eu/database, accessed 12 November 2020).

\section{Distribution}

Meloidogyne chitwoodi was first detected in the Netherlands in the 1980s. A review of old illustrations and old specimens of Meloidogyne suggests that it was probably already present in the 1930s. Meloidogyne fallax was detected for the first time in 1992 in a field near Baexem (NL) and described as a new species. In Belgium, M. chitwoodi and M. fallax were detected for the first time in 1996 but the presence of $M$. chitwoodi in oak forest soil, combined with the relatively high genetic distances between populations, also suggest a longer presence (Waeyenberge and Moens, 2001). In general, Meloidogyne spp. occur on a wide range of soil types, but in the Netherlands, M. chitwoodi and $M$. fallax are mainly found on sandy, peaty and light marine clay soils. In Belgium, both species are mostly found on sandy soils.
In a survey undertaken in 2006, M. chitwoodi and/or M. fallax were found in about $20 \%$ of the soil samples taken from sandy and peaty soils in the eastern region and sporadically in samples taken from the light marine clay soils in the western region of the Netherlands. A survey in vegetable and potato growing areas in Flanders in 1996-1997 showed that in 1\% of the 2877 samples, M. chitwoodi and/or M. fallax were present (Waeyenberge and Moens, 2001). Since then, more findings have been reported in Belgium and about one out of three fields sampled for carrot or black salsify production are found to be infested in some areas.

\section{Symptoms of damage}

Meloidogyne chitwoodi symptoms are very similar to those of $M$. fallax. Both species can infect roots (Fig. 48.1) and tubers (Fig. 48.2). Infected roots show small galls, typically without secondary roots as is the case with M. hapla. The spherical bodies of females may protrude from the root surface of small rootlets surrounded posteriorly by a large egg-filled sac which becomes dark brown with age.

Economically, the most significant form of damage due to M. chitwoodi and M. fallax is

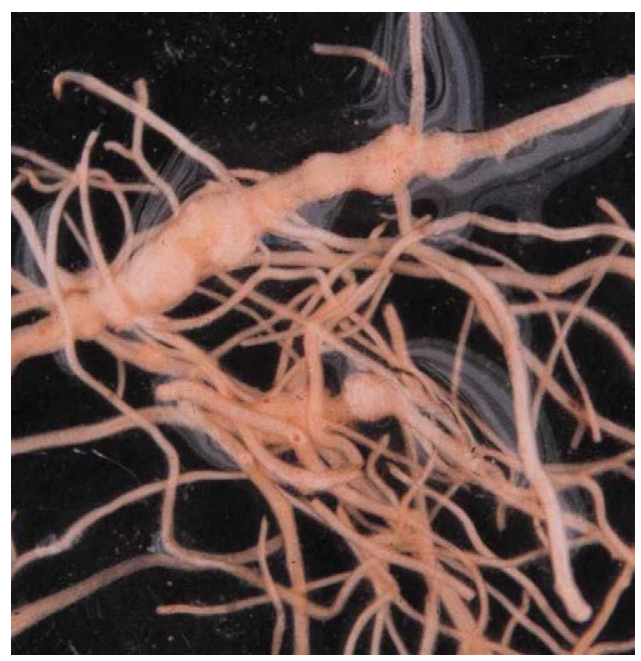

Fig. 48.1. Galling of potato roots caused by Meloidogyne chitwoodi. Photograph courtesy of Wageningen University \& Research, Field Crops. 


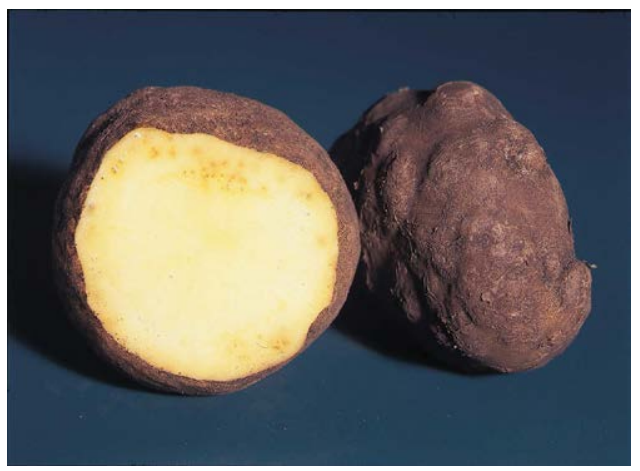

Fig. 48.2. Deformation of potato tubers caused by Meloidogyne chitwoodi. After peeling, egg masses (brownish spots) become visible. Photograph courtesy of Wageningen University \& Research, Field Crops.

quality loss due to tuber infection. Seed potatoes must be free of these quarantine species and can only be grown on fields free of $M$. chitwoodi and M. fallax. The development of external symptoms varies with cultivar and infection level. Low pre-plant densities of less than 10 juveniles per $100 \mathrm{ml}$ of soil can cause a total yield loss due to tuber quality defects. In some cases, tubers may be heavily infected without visible symptoms. Only at very high pre-plant densities of $>1000$ juveniles per $100 \mathrm{ml}$ of soil, growth and total yield is slightly reduced. In general, no yield losses of ware potatoes have been reported in the Netherlands or Belgium caused by M. chitwoodi or M. fallax.

\section{Biology and life cycle}

Meloidogyne chitwoodi and M. fallax are sedentary endoparasites. Their life cycle is comparable with most of the Meloidogyne spp. Under favourable conditions the life cycle of $M$. chitwoodi and M. fallax takes $6-8$ weeks. Soil temperature has a major influence on development and reproduction and hence the number of generations per year. Hatching starts at a soil temperature of $5^{\circ} \mathrm{C}$ and optimum temperature for reproduction is around $20^{\circ} \mathrm{C}$ (Khan et al., 2014). In the Netherlands and Belgium, M. chitwoodi and M. fallax can complete two and sometimes three generations per year. In the absence of a host plant the population density of both M. chitwoodi and
M. fallax decreases substantially and a decline of up to $95 \%$ has been reported especially during warm summers. During winter M. chitwoodi and M. fallax survive as juveniles in eggs, which has shown to be an important survival strategy.

\section{Interactions with other nematodes and pathogens}

Although root-knot nematodes have been reported to interact with bacterial wilt, Pseudomonas solanacearum and Erwinia spp. and Streptomyces scabies, and fungi such as Verticillium spp., Fusarium spp. and Rhizoctonia solani (Manzanilla-Lopéz et al., 2009) on potato elsewhere, interactions between M. chitwoodi or M. fallax and other pathogens in potato fields in the Netherlands and Belgium are not known.

\section{Recommended integrated nematode management (INM)}

A nematode control strategy, as part of an integrated crop management approach, has been promoted in the Netherlands since the end of the 1990s (Molendijk and Mulder, 1996). This INM strategy was developed to reduce the use and dependency on chemical nematicides and is based on four major pillars: prevention, inventory, crop rotation and supporting measures. In this integrated management strategy nematicides are only applied when necessary as a last resort.

\section{Prevention}

It is of great importance to avoid introduction of Meloidogyne infestations because damage thresholds are very low (zero tolerance for seed potatoes) and infestations are very hard or nearly impossible to eradicate.

Meloidogyne chitwoodi and M. fallax can be spread by infested soil attached to agricultural machinery and to propagation material or by infected planting material such as seed potatoes and flower bulbs (e.g. gladiolus and dahlia). Certified planting material and strict farm hygiene 
practices are needed to prevent spread of these quarantine organisms.

At the processing plants, tonnes of waste soil are collected and it is recommended that all the waste soil is brought back to the field where it came from but in practice this is almost impossible. The waste soil has to be treated to make sure it is free of this quarantine species. Inundation of waste soil is an effective option.

\section{Inventory}

In order to be able to take appropriate control measures, it is imperative to determine nematode species and population densities of a field by soil sampling. In general, soil samples are taken randomly in the upper $25 \mathrm{~cm}$ of the soil, collecting approximately $1.5 \mathrm{~L}$ soil per hectare. Detection levels increase strongly when samples are taken when the population is expected to be highest either after harvest of a good host and before the middle of November, when populations begin their natural decline. A more sensitive detection method, mainly used by seed potato growers, is a bioassay. Approximately $50 \mathrm{~L}$ of soil is taken randomly from 0.33 ha, homogenized and put in a container in which a sensitive potato cultivar is grown. After 3 months, newly formed tubers and soil are inspected for the presence of $M$. chitwoodi and/or M. fallax. Field inspection of roots and tap roots of intolerant host crops like carrot or black salsify also may reveal the presence of M. chitwoodi and M. fallax. It is important to know which Meloidogyne species is present because this will determine the options for control with crop rotation.

\section{Crop rotation}

Feasible crop rotation strategies to reduce population densities of M. chitwoodi and M. fallax to levels below the damage threshold of the succeeding crop are limited because of the wide host range of both species. The host suitability and tolerance of cash and cover crops for $M$. chitwoodi and M. fallax is shown in Fig 48.3.

Chicory and flax (Linum usitatissimum) are non-hosts, peas and barley are poor hosts. Many common bean cultivars are non-hosts for
M. fallax, but for M. chitwoodi this strongly depends on the cultivar. Recently, breeders of sugar beet developed a $M$. chitwoodi resistant sugar beet cultivar.

Growers can also include short season crops like lettuce and spinach in their rotation to reduce population densities of $M$. chitwoodi and M. fallax. These are good hosts for M. chitwoodi and M. fallax and act like trap crops. The nematodes penetrate and start to develop but the crop is harvested and roots are destroyed by soil cultivation before the nematodes can complete their life cycles.

Potato cultivars differ in tolerance for tuber damage symptoms. Therefore, it is recommended that farmers do not grow intolerant cultivars like 'Hansa' or 'Asterix'. At low to moderate infestation levels $(<100$ juveniles/100 ml soil) it is possible to harvest marketable tubers of more tolerant cultivars such as 'Donald' or 'Première'. Several Dutch breeders are currently developing potato cultivars with resistance against $M$. chitwoodi. These cultivars will be available within a few years and have a very high level of root and tuber resistance (no reproduction) combined with tolerance (no symptoms). Meloidogyne chitwoodi resistant fodder radish cultivars (Raphanus sativus, Teklu et al., 2014) are recommended as a cover crop after cereals, seed potato or carrots production (www.aaltjesschema.nl and www.Best4soil.eu, accessed 12 November 2020).

In general, the extent of control of $M$. chitwoodi and M. fallax by crop rotation is insufficient for seed potato growers because of the zero tolerance needed.

Weed control is of major importance for zero tolerance when a non-host or poor host cash crop is grown for nematode control. Many weeds are good host plants (Rich et al., 2009) and will diminish the effect of the poor/non-host crop on nematode population reduction.

\section{Additional measures}

\section{Nematicides}

The fumigant Monam (metam sodium) and some non-fumigant granular nematicides (Vydate, Nemathorin, Velum) are registered in the Netherlands and/or Belgium for control of Meloidogyne spp. in potato. Due to imposed restrictions 


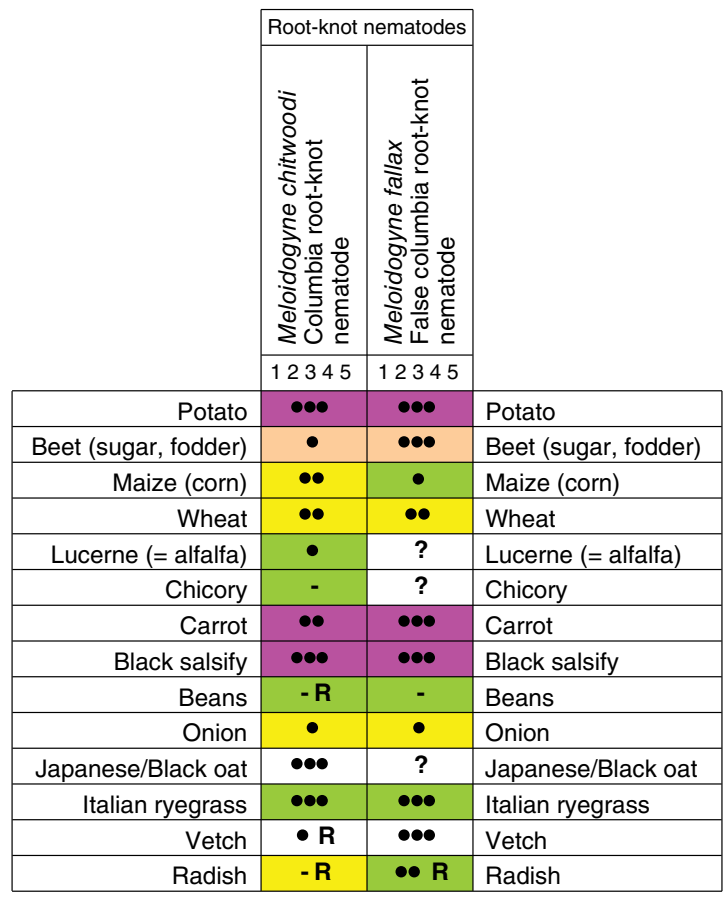

\begin{tabular}{|l|c|}
\hline \multicolumn{2}{|c|}{ Legend damage } \\
\hline & Unknown \\
\hline & None \\
\hline & Little (0-15\%) \\
\hline & Medium (16-35\%) \\
\hline & Serious (36-100\%) \\
\hline
\end{tabular}

Fig. 48.3. Nematode scheme; host suitability and tolerance of cash and cover crops for Meloidogyne chitwoodi and M. fallax. Figure courtesy of Wageningen University \& Research, Field Crops.

\begin{tabular}{|c|c|}
\hline \multicolumn{2}{|c|}{ Legend propagation } \\
\hline-- & Active decline of population \\
\hline$?$ & Unknown \\
\hline- & Non host \\
\hline$\bullet$ & Poor host \\
\hline$\bullet \bullet$ & Moderate host \\
\hline$\bullet \bullet$ & Good host \\
\hline R & Variety dependent \\
\hline S & Serotype dependent \\
\hline i & Some information \\
\hline
\end{tabular}


and the requirement of sealing the soil surface with virtually impermeable film to avoid evaporation, the use of Monam is no longer an economically feasible alternative for potato growers. Populations of M. chitwoodi and/or M. fallax can be reduced strongly by fumigation but it does not eliminate populations and therefore fumigation is an insufficient control measure for growers of seed potatoes. The granular nematicides act as nematostatics, paralysing the nematode for short period of time. These nematicides, when broadcast applied, can reduce galling to an acceptable level but have only a limited effect on reproduction. In-furrow application is mostly insufficient to achieve the required control.

\section{Anaerobic soil disinfestation (ASD)}

ASD refers to the incorporation of a large amount (>40 t/ha) of easily decomposable organic amendments, with supplemental irrigation and subsequent covering the soil with an airtight foil. The complete depletion of oxygen within 24 hours after tarping (Blok et al., 2000) and the volatile compounds produced during ASD are lethal for several soil-borne fungi and plant parasitic nematodes such as potato cyst nematodes (Globodera spp.), root lesion nematodes (Pratylenchus penetrans) and Meloidogyne spp. (Lamers et al., 2010). Meloidogyne chitwoodi populations can be reduced by more than $95 \%$. Due to the high cost of ASD of approximately $€ 4000 /$ ha, ASD is still not an economic alternative method for ware potato growers. In addition, because populations will not be fully eliminated by ASD, this method is not suitable for the zero tolerance needed by seed potato growers.

\section{Inundation (flooding)}

Flooding fields for 12 to 14 weeks at soil temperatures above $16^{\circ} \mathrm{C}$ is very effective for control of several soil fungi, weeds and nematodes. Several field experiments in the Netherlands on marine clay soils showed that $M$. chitwoodi could be eliminated by inundation for 14 weeks during summer. Inundation, originally used by bulb growers to control the stem nematode Ditylenchus dipsaci, is now adapted by seed potato growers to sanitize M. chitwoodi infested fields. The disinfestation process with inundation can be accelerated by addition of organic material.

\section{Optimization of nematode management}

In addition to nematodes, the farmer has to consider all elements of soil quality in his fields. Therefore, the INM tools used for nematode control must not adversely affect soil quality. Optimizing nematode management will only be achieved when an integrated approach including soil quality becomes realistic. In the era of precision farming, big data and computer technology this overall management is on the horizon.

Implementation of a boost year could be a great help in optimizing INM. A boost year means eliminating all cash crops from the rotation and using multiple inputs to improve soil quality, including nematode control. Farmers in the north-east of the Netherlands exchange their barley crop for a clean fallow until June to control volunteer potatoes and other weeds in April/May. In June they sow marigolds (Tagetes patula) to control the root lesion nematode Pratylenchus penetrans. Long-term field experiments showed that the increase of potato and sugar beet yield made this boost year very profitable (Chapter 40).

Most major cash crops are moderate to good hosts for M. chitwoodi and M. fallax. Breeding for resistance in major cash crops like maize, cereals and legumes would enhance the opportunities to control M. chitwoodi and M. fallax by crop rotation in the potato crop.

\section{Future research requirements}

To improve nematode support systems used by growers when setting up their crop rotation, quantitative research on reproduction (population development) and tolerance (relationship between initial population and yield) of major cash crops and cultivars is needed. Methods for disinfestation of propagation material and economically applicable sanitation techniques for waste products (soil and water) in the processing industry and tare soil of potato storage need to be developed to minimize the spread of M. chitwoodi and M. fallax. As the damage threshold of many crops for M. chitwoodi and M. fallax is very low, research to improve detection techniques by increasing the detection limit, will prevent unexpected damage and economic losses. 


\section{Outlook: anticipating future developments}

Climate change will lead to warmer summers and milder winters. This may lead to the introduction and spread of Meloidogyne spp. from warmer climates in southern Europe to the more temperate regions in the north. The presence of root-knot nematodes in greenhouses is also a focal point for spread. Increasing temperatures will also have an effect on population dynamics. Most likely, more generations will be formed during the cropping season. If increased soil temperatures during winter lengthen the activity of nematode antagonists of M. chitwoodi and M. fallax this might lead to a stronger winter decline. Very mild winters could cause an increase in root-knot on surviving weeds and volunteers of host crops.

\section{References}

Blok, W.J., Lamers, J.G., Termorshuizen, A.J. and Bollen, G.J. (2000) Control of soilborne plant pathogens by incorporating fresh organic amendments followed by tarping. Phytopathology 90, 253-259.

den Nijs, L., Brinkman, H. and Sommen, van der A.T.C. (2004) A Dutch contribution to knowledge on phytosanitary risk and host status of various crops for Meloidogyne chitwoodi Golden et al., 1980 and $M$. fallax, 1996: an overview. Nematology 6, 303-312.

Khan, A., Wesemael, W. and Moens, M. (2014) Influence of temperature on the development of the temperate root-knot nematodes Meloidogyne chitwoodi and M. fallax. Russian Journal of Nematology 22(1), 1-9.

Lamers, J.G., Runia, W.T., Molendijk, L.P.G. and Bleeker, P.O. (2010) Perspectives of anaerobic soil disinfestation. Acta Horticulturae 883, 277-283.

Manzanilla-López, R.H. and Starr, J.L. (2009) Interaction with other pathogens. In: Perry, R.N., Moens, M. and Starr, J.L. (eds) Root-knot Nematodes. CABI Publishing, Wallingford, UK, pp. 226-230.

Molendijk, L.P.G. and Mulder, A. (1996) The Netherlands, nematodes and potatoes; old problems are here again. Potato Research 39, 471-477.

Rich, J.R., Brito, J.A., Kaur, R. and Ferrell, J.A. (2009) Weed species as hosts of Meloidogyne: a review. Nematropica 39, 157-185.

Teklu, M.G., Schomaker, C.H. and Been, T.H. (2014) Relative susceptibilities of five fodder radish varieties (Raphanus sativus var. Oleiformis) to Meloidogyne chitwoodi. Nematology 16, 577-590.

Waeyenberge, L. and Moens, M. (2001) Meloidogyne chitwoodi and M. fallax in Belgium. Nematologica Mediterranea 29, 91-97.

Wesemael, W.M.L., Viaene, V. and Moens, M. (2011) Root-knot nematodes (Meloidogyne spp.) in Europe. Nematology 13, 3-16. 